Research Article

\title{
Evidence for the involvement of the monoaminergic system in the antidepressant-like activity of methanolic extract of Bacopa monnieri in albino mice
}

\author{
Chandrashekaran Girish $^{1}$, Shweta Oommen ${ }^{2}$, Raj Vishnu ${ }^{2}$
}

\begin{abstract}
${ }^{1}$ Department of Pharmacology, Jawaharlal Institute of Postgraduate Medical Education and Research (JIPMER), Dhanwanthri Nagar, Pondicherry- 605 006, India ${ }^{2}$ Department of Pharmacology, Pondicherry Institute of Medical Sciences (PIMS), Kalapet, Pondicherry- 605 014, India
\end{abstract}

Received: 15 March 2016 Accepted: 15 April 2016

\section{*Correspondence to:}

Dr. Chandrashekaran Girish, Email: gcnx@rediffmail.com

Copyright: (C) the author(s), publisher and licensee Medip Academy. This is an openaccess article distributed under the terms of the Creative Commons Attribution NonCommercial License, which permits unrestricted noncommercial use, distribution, and reproduction in any medium, provided the original work is properly cited.

\begin{abstract}
Background: Depression is a common illness worldwide, with an estimated 121 million people affected. The efficacy of currently available drugs for treating depression often lack consistency and many of them exert undesirable side effects. This emphasises on the need for newer drugs for the treatment of major depression.

Methods: The present study evaluated the antidepressant-like activity of methanolic extract of Bacopa monnieri in mouse forced swimming test (FST) and tail suspension test (TST), which are predictive models of antidepressant activity. An attempt was also made to understand the involvement of the monoaminergic system and the opioid system in Bacopas' antidepressant activity. Albino mice were treated with vehicle, fluoxetine $(20 \mathrm{mg} / \mathrm{kg})$, or Bacopa monnieri $(20,40,80$, and $120 \mathrm{mg} / \mathrm{kg}$ ) orally and evaluated in FST and TST. The actophotometer performance was also examined after different treatments. For understanding the mechanisms, different receptor antagonists were used.

Results: Bacopa monnieri produced a significant reduction in the duration of immobility, with better activity at $80 \mathrm{mg} / \mathrm{kg}$ dose. Furthermore, the antidepressant-like action produced by Bacopa monnieri was abolished by the pre-treatment of mice with p-chlorophenylalanine $(100 \mathrm{mg} / \mathrm{kg}$, i.p., a serotonin synthesis inhibitor), pindolol $(10 \mathrm{mg} / \mathrm{kg}$, i.p., a $\beta$-adrenoceptor blocker/5HT1A/1B receptor antagonist, ketanserin $(5 \mathrm{mg} / \mathrm{kg}$, i.p., a 5HT2A/2B receptor antagonist), prazosin (1 mg/kg, i.p., an $\alpha 1$-adrenoceptor antagonist), and yohimbine $(1 \mathrm{mg} / \mathrm{kg}$, i.p., an $\alpha 2$-adrenoceptor antagonist), but not with ondansetron (1 mg/kg, i.p., a 5HT3 receptor antagonist) and naloxone (1 mg/kg, i.p., an opioid receptor antagonist).

Conclusions: These findings suggest that the antidepressant-like effect produced by Bacopa monnieri may be mediated through an interaction with the serotonergic and noradrenergic nervous system. The antidepressant doses of Bacopa monnieri had no effect on the locomotor activity of mice.
\end{abstract}

Keywords: Antidepressant-like effect; Bacopa monnieri; Mice; Noradrenergic; Serotonin; Tail suspension test

\section{INTRODUCTION}

Depression is a mental disorder with an estimated 121 million people affected. The WHO has identified the depressive disorder as a prevalent mental health disorder and the fourth leading cause of impaired activities and premature death in the world. It is conjoined with momentous morbidity and mortality, and psychosocial and occupational impairment. ${ }^{1}$ During the last few years, there has been a considerable advancement in the drug treatment for depression. However, the efficacy of currently available drugs for treating depression often lack in consistency and many of them may result in side effects. $^{2}$ This emphasises the need for more research to identify newer drugs in the treatment of major depression and to understand their mechanisms.

A number of herbal medicines or their active principles have been evaluated for psychiatric conditions with promising benefits, such as Piper methysticum, Ginkgo 
biloba, Lavandula angustifolia, Hypericum perforatum, ursolic acid, ellagic acid, and many more., Bacopa monnieri (Brahmi) is one among such plants that has showed antidepressant action in few earlier reports. Bacopa monnieri (BM) is a perennial creeping annual plant found all over the Indian subcontinent. ${ }^{5}$ Ayurvedic physicians have used Bacopa monnieri to treat behavioural abnormalities, including anxiety, poor cognition, obsessive compulsive disorders, panic attacks, hysteria, and lack of concentration. Bacopa monnieri also acts as a neuroprotective agent against toxicants like glutamate, aluminium and nitric oxide. ${ }^{6-8}$ Antioxidant effects of Bacopa monnieri in different areas of the rat brain involved in memory, such as the hippocampus, frontal cortex, and striatum have been documented. ${ }^{9}$ Even though the antidepressant activity of Bacopa monnieri has been reported, there are no studies done to establish their mechanism of action.

Studies have suggested the importance of the monoaminergic system in the pathophysiology of depression and the antidepressant drugs that may act by modulation of these systems. ${ }^{10,11}$ Reduction in brain serotonin and noradrenaline has been known to be the most important etiological factors in depression. The most widely used antidepressant drug group, selective serotonin reuptake inhibitors (SSRIs), can act by increasing the extracellular availability of serotonin by acting through serotonergic (5HT) receptors. ${ }^{12-15}$ Apart from the well-established monoaminergic system, some of the antidepressants can act through the opioid system. ${ }^{16}$ So it is pertinent to explore the possible role of monoamines, such as serotonin and noradrenaline, along with the opioid system in the antidepressant-like effect of lead compounds. Therefore, the present work was designed to examine the role of the monoaminergic and the opioid system in the antidepressant-like activity of Bacopa monnieri by using behavioural tests in mice.

\section{METHODS}

\section{Animals}

Male albino mice (3-4 months old, 25-30 g) were maintained at $22-25^{\circ} \mathrm{C}$ with free access to water and food, under a 12 hours light-12 hours dark cycle. They were randomly distributed into specified experimental groups. All experiments were carried out between 9:00 and 17:00 $h$, with each animal used only once. The procedures in this study were approved by the animal ethics committee of the institution and were performed in accordance with the CPCSEA guidelines.

\section{Drugs}

All the drugs used were procured from standard commercial suppliers. Methanolic extract of Bacopa monnieri was gifted by natural remedies pvt. limited, Bangalore, India. The phytochemical analysis revealed the presence of total bacosides, $10.8 \%$ w/w. Fluoxetine
$(( \pm)-\mathrm{N}-$ Methyl- $\gamma$-[4 (trifluoromethyl) phenoxy] benzene propanamine hydrochloride), p-chlorophenylalanine (PCPA), pindolol (1-(1H-indol-4-yloxy)-3(isopropylamino)-2-propanol), ketanserin (3-(2-[4-(4fluorobenzoyl)-1-piperidinyl]ethyl)-2,4(1H,3H)

quinazolinedione (+)-tartrate salt), ondansetron $(1,2,3,9$ tetrahydro-9-methyl-3-[(2-methyl-1H-imidazol-1-

yl)methyl]-4H-carbazol-4-one hydrochloride), prazosin (1-(4-amino-6,7-dimethoxy-2-quinazolinyl)-4-(2-

furanylcarbonyl) piperazine hydrochloride) and yohimbine (17-Hydroxy-yohimban-16-carboxylic acid methyl ester hydrochloride) were obtained from Sigma Chemical Co., USA. Bacopa monnieri was suspended in $0.5 \%$ of gum acacia and given orally. The above mentioned receptor antagonists were administered intraperitoneally to mice after dissolving them either in saline or $1 \%$ Tween 80 , in a constant volume of $10 \mathrm{mg} / \mathrm{ml}$ body weight. The control groups received appropriate vehicles/and were also assessed simultaneously.

\section{Experimental procedure}

\section{- $\quad$ Acute treatment with Bacopa monnieri}

Animals received a single oral dose of vehicle (gum acacia, $0.5 \%)$, Bacopa monnieri, or fluoxetine $(20 \mathrm{mg} / \mathrm{kg}$, p.o.) and underwent forced swimming test (FST) or tail suspension test (TST) after 1 hour. Bacopa monnieri was given at four different doses of 20, 40, 80, and 120 $\mathrm{mg} / \mathrm{kg}$, to identify any dose-response relationship. The doses were selected based on previous reports, which had used doses ranging from 40 to $120 \mathrm{mg} / \mathrm{kg} .{ }^{17,18}$ Hence, we have also worked on the same dose range, including a lower dose of $20 \mathrm{mg} / \mathrm{kg}$. Fluoxetine $(20 \mathrm{mg} / \mathrm{kg}$, p.o., single dose) was also administered 1 hour prior to the tests and used as a positive control. ${ }^{19,20}$ The group that received gum acacia $(0.5 \%)$ alone was designated as the control group.

- Evaluation of Bacopa monnieri's possible mechanism of antidepressant-like action using FST

Mice were pre-treated with various receptor antagonists or their respective vehicles and after $30 \mathrm{~min}$, Bacopa monnieri was administered (80 $\mathrm{mg} / \mathrm{kg}$, p.o.). FST was conducted 1 hour after BM treatment. The dose and pretreatment period of all the antagonists were decided based on earlier reports. $3,18,20$

Role of the serotonergic system in the antidepressant-like effect of Bacopa monnieri in FST

Animals were administered PCPA injection $(100 \mathrm{mg} / \mathrm{kg}$ i.p., a serotonin synthesis inhibitor) once daily for four consecutive days as a pre-treatment. On the fourth day, 30 minutes after the last injection of PCPA, mice were treated with either a vehicle or BM and were tested by FST, 1 hour later. ${ }^{20}$ The possible involvement of 5$\mathrm{HT} 1 \mathrm{~A} / 1 \mathrm{~B}$, 5-HT2A/2C, and 5-HT3 receptors in the antidepressant-like effect of Bacopa monnieri was further 
investigated by using respective receptor antagonists. Accordingly, animals were pre-treated with pindolol (10 $\mathrm{mg} / \mathrm{kg}$, i.p., a 5-HT1A/1B receptor antagonist and a $\beta$ adrenoceptor blocker), ketanserin (5 mg/kg i.p., a $5 \mathrm{HT} 2 \mathrm{~A} / 2 \mathrm{C}$ receptor antagonist) or ondansetron $(1 \mathrm{mg} / \mathrm{kg}$ i.p., 5HT3 receptor antagonist). After $30 \mathrm{~min}$, they received Bacopa monnieri or vehicle and were tested with FST 1 hour later. ${ }^{18,20}$

Role of the noradrenergic system in the antidepressantlike action of Bacopa monnieri in FST

Animals were pre-treated with prazosin $(1 \mathrm{mg} / \mathrm{kg}$, i.p., an $\alpha 1$-adrenoceptor antagonist) or yohimbine (1 mg/ kg, i.p., an $\alpha 2$-adrenoceptor antagonist). After 30 minutes, they received Bacopa monnieri or vehicle and were tested using FST, 1 hour later. ${ }^{3}$

Role of the opioid receptors in the antidepressant action of Bacopa monnieri in FST

Animals were pre-treated with naloxone $(1 \mathrm{mg} / \mathrm{kg}$, i.p., a non-selective opioid receptor antagonist). After 30 minutes, they received Bacopa monnieri or vehicle and were tested with FST after an additional 1 hour. ${ }^{20}$

\section{Behavioural analysis}

\section{Tail suspension test (TST)}

The method was described by Steru et al. ${ }^{21}$ The principle is based on the fact that the mice, in an inescapable and stressful situation, will adopt an immobile posture. Prior to this test, the animals were acoustically and visually isolated. Then the stressful situation was created by suspending the mice by their tail on a thin horizontal steel rod, $50 \mathrm{~cm}$ above the surface with the help of an adhesive tape placed approximately $1 \mathrm{~cm}$ from the tip of the tail, for a short period of 6 minutes. Mice were considered to be immobile when they hung passively without any motion.

\section{Forced swimming test (FST)}

In this study, a slightly modified method described by Porsolt et al was used. ${ }^{22}$ Briefly, a five litre glass cylinder, which was filled with $15 \mathrm{~cm}$ of water, was used for FST. Then each mouse were placed in this and observed for duration of 6 minutes. The immobility period was recorded manually during the 6 minutes test. The mouse was considered immobile when it floated motionlessly or made only those movements necessary to keep its head above the water surface. After the test, the animals were removed from the water and dried with a towel. The water was replaced after each test.

\section{Locomotor activity of mice using digital actophotometer}

The method described by Boissier and Simon with slight modification was used. This procedure was performed to rule out any change induced by the test drug in the locomotors activity of the mice. The actophotometer contains a square arena $(30 \times 30 \mathrm{~cm})$ with walls that are fitted with photocells just above the floor level. Each time the animal crosses the light beam, it will be recorded by this device automatically. The mice after receiving the test drug/vehicle, are placed in this arena and the digital locomotors scores were noted for the next 6 minutes. ${ }^{23,24}$ For the mechanistic study, the doses of all the receptor antagonists were selected as per the previous reports. $^{10,18,20,25-29}$ At these selected dose levels, the locomotors activity of mice was not altered by these antagonists.

\section{Statistical analysis}

The data were represented as mean \pm S.D. The difference between groups was calculated by one-way ANOVA or two-way ANOVA followed by Bonferroni test as post hoc comparison where appropriate. Probability values less than 0.05 ( $\mathrm{P}$ value $<0.05$ ) were considered as statistically significant.

\section{RESULTS}

\section{Treatment with Bacopa monnieri on the immobility time in FST of mice}

Bacopa monnieri was given to the mice at the doses of 20 , 40,80 , and $120 \mathrm{mg} / \mathrm{kg}$ orally and the immobility time was noted in the FST. The results are presented in (Figure 1). It was observed that after the administration of Bacopa monnieri at different dose levels, the immobility time of mice in FST was decreased significantly $[\mathrm{F}(5,30)=10.86$, $\mathrm{P}<0.001]$. The positive control group, which received fluoxetine $(20 \mathrm{mg} / \mathrm{kg}$, p.o.), also significantly decreased $(\mathrm{P}<0.001)$ the immobility time, which was comparable to the effects of Bacopa monnieri (40, 80 and $120 \mathrm{mg} / \mathrm{kg}$ ).

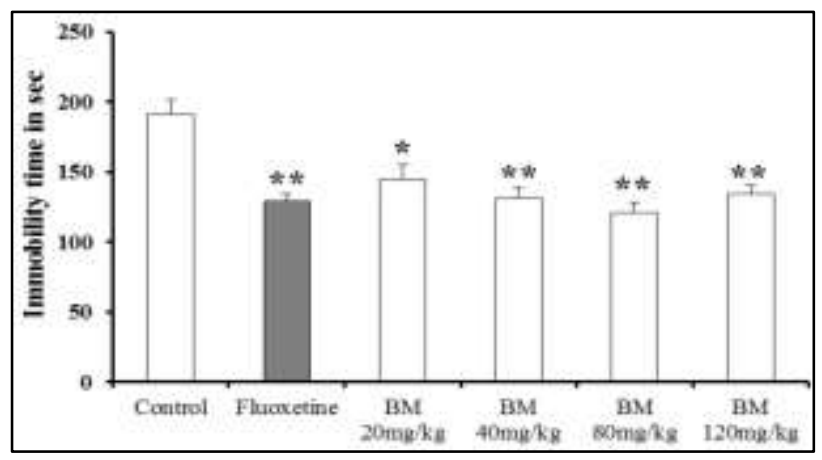

Figure 1: Effect of acute administration of Bacopa monnieri and fluoxetine in mouse forced swimming test. Bacopa monnieri $(20,40,80$ and $100 \mathrm{mg} / \mathrm{kg})$ and fluoxetine $(20 \mathrm{mg} / \mathrm{kg})$ were administered p.o., 1 hour before the test. Each column represents mean \pm S.D.

from 6 animals per group. $* \mathbf{P}<0.01, * * \mathbf{P}<0.001$ when compared with the control group. BM- Bacopa monnieri. 


\section{Treatment with Bacopa monnieri on the immobility time in TST of mice}

As depicted in (Figure 2), Bacopa monnieri, when administered at graded doses of 40,80 , or $120 \mathrm{mg} / \mathrm{kg}$, produced a statistically significant reduction in the immobility time as compared to the vehicle-treated group $[F(5,30)=6.65, P=0.003]$. However, at $20 \mathrm{mg} / \mathrm{kg}$, this plant extract was found to be ineffective in reducing the immobility time. Fluoxetine treatment also reduced the duration of immobility time significantly. Based on the FST and TST results, the dose $80 \mathrm{mg} / \mathrm{kg}$ of Bacopa monnieri was identified as the most effective dose. Therefore, the dose level of $80 \mathrm{mg} / \mathrm{kg}$ of Bacopa monnieri was employed in the experiments to detect the possible mechanism of action.

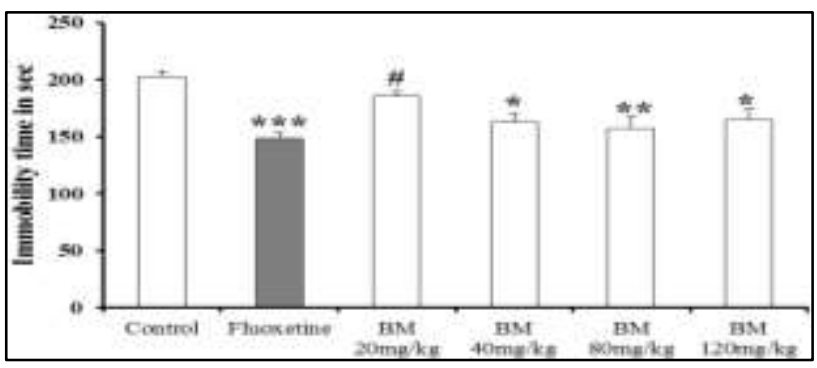

Figure 2: Effect of acute administration of Bacopa monnieri and fluoxetine in mouse tail suspension test.

Bacopa monnieri $(20,40,80$ and $100 \mathrm{mg} / \mathrm{kg})$ and fluoxetine $(20 \mathrm{mg} / \mathrm{kg})$ were administered p.o., 1 hour in before the test. Each column represents mean \pm S.D.

from 6 animals per group. $* \mathbf{P}<0.05$, $* * \mathbf{P}<0.01$, $* * * \mathbf{P}<0.001$ when compared with the control group. \#P<0.05 as compared with fluoxetine group. BMBacopa monnieri.

Effect caused by Bacopa monnieri on the locomotors activity of mice in the actophotometer

The treatment of Bacopa monnieri at any of the four doses $(20,40,80$, and $120 \mathrm{mg} / \mathrm{kg}$, p.o.) have not altered the locomotors activity of mice $[\mathrm{F}(5,30)=0.785, \mathrm{P}=$ 0.571] (Table 1). A similar effect was also observed with fluoxetine, having no influence on the locomotors function when tested in the actophotometer.

Role of the serotonergic system in the antidepressant action of Bacopa monnieri in FST

For this, PCPA, pindolol, ketanserin, or ondansetron were administered 30 minutes prior to Bacopa monnieri and the FST was performed 1 hour after Bacopa monnieri treatment. The results in [Figure $3(\mathrm{~A})$ ] show that pretreatment of mice with PCPA $(100 \mathrm{mg} / \mathrm{kg}$, once a day for 4 consecutive days) significantly blocked the reduction in the immobility time elicited by Bacopa monnieri $(80$ $\mathrm{mg} / \mathrm{kg}$, p.o.) in the FST. Two-way ANOVA revealed a significant effect of Bacopa monnieri treatment $[\mathrm{F}(1,20)=4.45, \quad \mathrm{P}=0.047], \quad \mathrm{PCPA}$ pre-treatment
$[\mathrm{F}(1,20)=11.63, \mathrm{P}=0.0028]$, and BM-PCPA interaction $[\mathrm{F}(1,20)=10.68, \mathrm{P}=0.0038]$. Furthermore, the reduction in immobility time caused by Bacopa monnieri $(80 \mathrm{mg} / \mathrm{kg}$, p.o.) was also abolished by pindolol pre-treatment of mice at $10 \mathrm{mg} / \mathrm{kg}$, i.p. [Figure 3 (B)]. There was a significant effect of $\mathrm{BM}[\mathrm{F}(1,20)=32.04, \mathrm{P}=0.0001]$, pindolol $[\mathrm{F}(1,20)=22.88, \mathrm{P}=0.0001]$, and $\mathrm{BM}$-pindolol interaction $[\mathrm{F}(1,20)=23.62, \mathrm{P}=0.0001]$. The antidepressant-like activity produced by Bacopa monnieri was also prevented by the pre-administration of ketanserin $(5 \mathrm{mg} / \mathrm{kg}$, i.p.) [Figure 3 (c)] [ketanserin pre-treatment: $F(1,20)=10.66$, $\mathrm{P}=0.0039$, BM treatment: $\mathrm{F}(1,20)=13.59, \mathrm{P}=0.0015$, BMketanserin interaction: $\mathrm{F}(1,20)=13.75, \mathrm{P}=0.0014]$, but not with ondansetron (1 $\mathrm{mg} / \mathrm{kg}$, i.p.) [Figure 3 (d)] [ondansetron pre-treatment: $\mathrm{F}(1,20)=0.023, \mathrm{P}=0.871$, BM treatment: $\mathrm{F}(1,20)=60.71, \quad \mathrm{P}=0.001, \quad \mathrm{BM}$-ondansetron interaction: $\mathrm{F}(1,20)=3.74, \mathrm{P}=0.08]$.

\section{Table 1: Effect of acute treatment with Bacopa monnieri on the locomotors activity in the actophotometer performance of mice.}

\begin{tabular}{|lc|}
\hline Drug & Number of crossings \\
\hline Vehicle & $273.40 \pm 11.97$ \\
\hline Fluoxetine, $20 \mathrm{mg} / \mathrm{kg}$ & $256.25 \pm 4.74$ \\
\hline Bacopa monnieri, $20 \mathrm{mg} / \mathrm{kg}$ & $247.50 \pm 9.10$ \\
\hline Bacopa monnieri, $40 \mathrm{mg} / \mathrm{kg}$ & $267.60 \pm 14.79$ \\
\hline Bacopa monnieri, $80 \mathrm{mg} / \mathrm{kg}$ & $278.20 \pm 13.86$ \\
\hline Bacopa monnieri, $120 \mathrm{mg} / \mathrm{kg}$ & $240.60 \pm 22.10$ \\
\hline
\end{tabular}

Results are expressed as mean \pm S.E.M. of 6 animals. Mice received single dose of vehicle (gum acatia, $0.5 \%$ ) or one of the above drugs, before being tested in actophotometer.

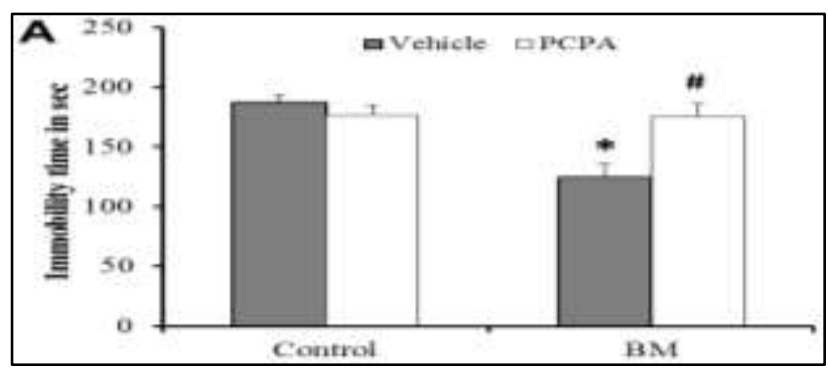

Figure 3 (A): Effect of pre-treatment of mice with PCPA (100 mg/kg, i.p., panel A).

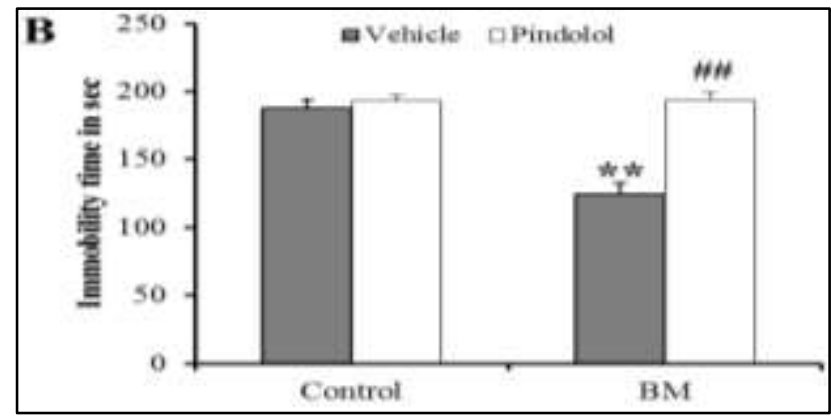

Figure 3 (B): Effect of pre-treatment of mice with pindolol (10 mg/kg, i.p., panel B). 


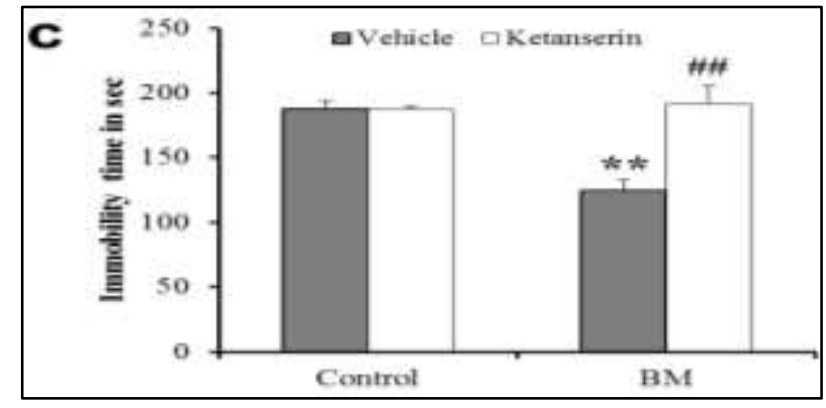

Figure 3 (C): Effect of pre-treatment of mice with ketanserin (5 mg/kg i.p., panel $\mathrm{C}$ ).

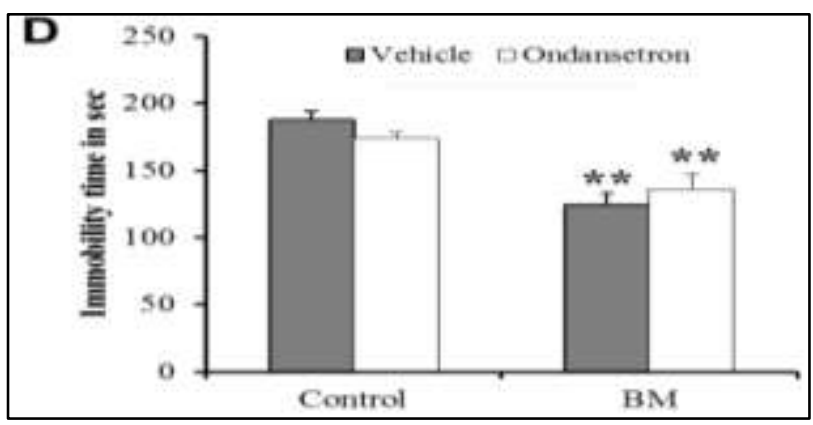

Figure 3 (D): Effect of pre-treatment of mice with ondansetron (1mg/kg i.p., panel D). On the immobility time of Bacopa monnieri $(80 \mathrm{mg} / \mathrm{kg}$ p.o.) in the forced swimming test. Each column represents the mean \pm SD of 6 animals. * $\mathbf{P}<0.01, * * \mathbf{P}<0.001$ when compared with the vehicle treated control. ${ }^{\#} \mathbf{P}<0.01,{ }^{\#} \mathbf{P}<0.001$ as compared with Bacopa monnieri alone. BM- Bacopa monnieri.

Role of the noradrenergic system in the antidepressantlike action of Bacopa monnieri in FST

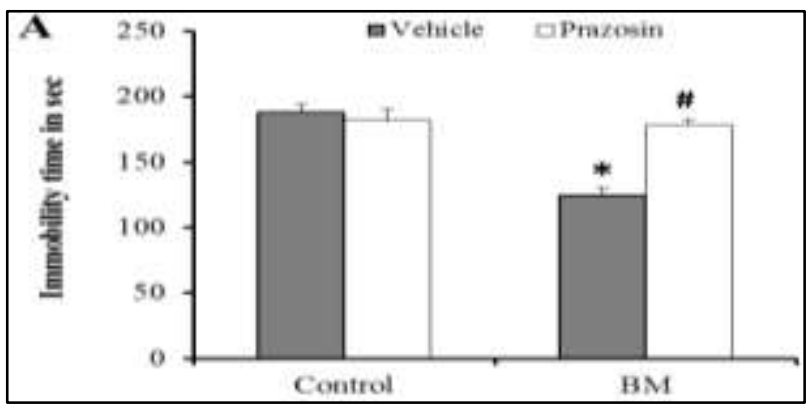

Figure 4 (A): Effect of pre-treatment of mice with prazosin (1mg/kg i.p., panel A).

The adrenergic blockers, prazosin or yohimbine was given $30 \mathrm{~min}$ before Bacopa monnieri and the FST was performed 1 hour after Bacopa monnieri administration. The antidepressant-like effect produced by Bacopa monnieri $(80 \mathrm{mg} / \mathrm{kg}$, p.o.) was significantly reversed by pretreatment of mice with prazosin $(1 \mathrm{mg} / \mathrm{kg}$, i.p. $)$ [Figure 4 (A)] or yohimbine (1 mg/kg, i.p.) [Figure 4 (B)]. A two-way ANOVA revealed a significant effect of BM
[F $(1,20)=26.96, \mathrm{P}<0.0001]$, prazosin $[\mathrm{F}(1,20)=14.02$, $\mathrm{P}=0.0013]$, and $\mathrm{BM}$-prazosin interaction $[\mathrm{F}(1,20)=22.28$, $\mathrm{P}=0.001]$. Similarly, the pre-treatment with yohimbine also had a significant effect in reversing the Bacopa monnieri-induced reduction in the immobility time [yohimbine pre-treatment: $\mathrm{F}(1,20)=12.43, \mathrm{P}=0.002, \mathrm{BM}$ treatment: $\mathrm{F}(1,20)=23.12, \mathrm{P}=0.0001, \mathrm{BM}$-yohimbine interaction: $\mathrm{F}(1,20)=14.18, \mathrm{P}=0.001]$.

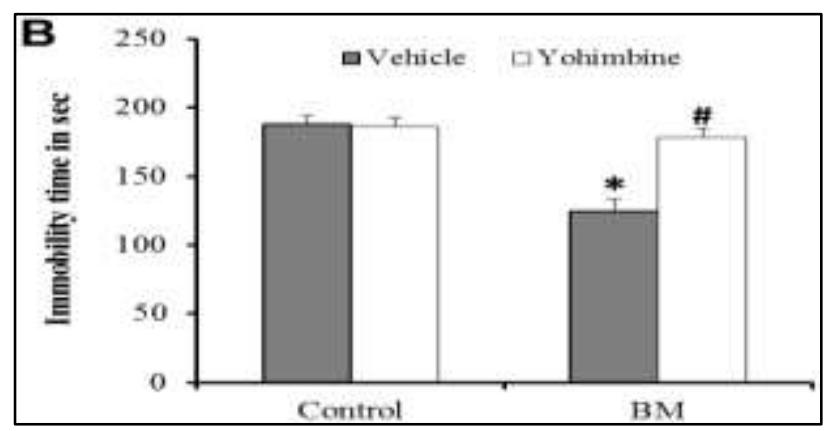

Figure 4 (B): Effect of pre-treatment of mice with yohimbine (1 mg/kg i.p., panel B) in the forced swimming test. Each column represents the mean \pm SD of 6 animals. $* P<0.001$ when compared with the vehicle treated control. ${ }^{\#} \mathbf{P}<\mathbf{0 . 0 0 1}$ as compared with

Bacopa monnieri alone. BM- Bacopa monnieri.

Role of opioid receptors in the antidepressant-like action of Bacopa monnieri in FST

Naloxone is a non-selective opioid receptor antagonist and was administered 30 minutes before Bacopa monnieri administration. Then the forced swimming test was performed after 1 hour. The pre-treatment of mice with naloxone $(1 \mathrm{mg} / \mathrm{kg}$, i.p) was found to be ineffective in reversing the reduction of the immobility period caused by Bacopa monnieri ( $80 \mathrm{mg} / \mathrm{kg}$, p.o.) in mice (Figure 5). The post-hoc analysis did not show significant differences of $\mathrm{BM}[\mathrm{F}(1,20)=43.51, \mathrm{P}<0.001]$, naloxone pretreatment $[\mathrm{F}(1,20)=2.68, \mathrm{P}=0.117]$, and $\mathrm{BM}$-naloxone interaction $[\mathrm{F}(1,20)=1.209, \mathrm{P}=0.285]$.

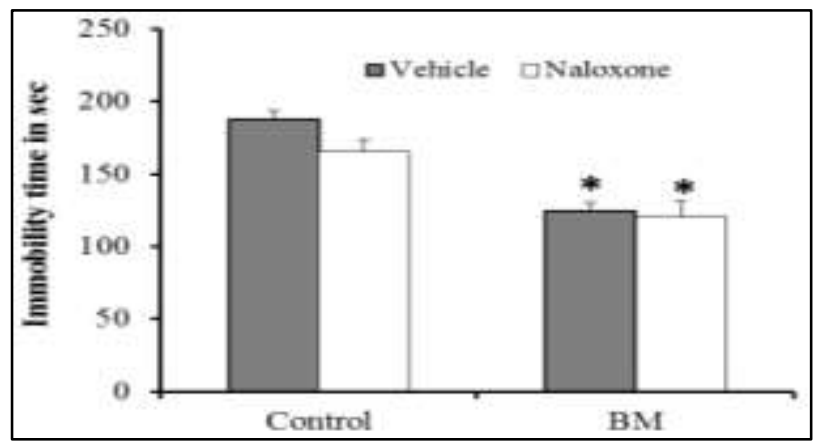

Figure 5: Effect of pre-treatment of mice with naloxone $(1 \mathrm{mg} / \mathrm{kg}$ i.p.) in the forced swimming test. Each column represents the mean \pm SD of 6 animals. $* \mathbf{P}<0.01$ when compared with the vehicle treated control. BM-Bacopa monnieri. 


\section{DISCUSSION}

The present study has demonstrated that Bacopa monnieri given by the oral route showed an antidepressant-like activity in the FST and TST models in mice. The locomotors activity of mice was unaltered in the presence of Bacopa monnieri, indicating the absence of any psych stimulant effect of this plant drug. To the best of our knowledge, this is the first study that attempted to establish the possible antidepressant mechanism of action of Bacopa monnieri. It was observed that the antidepressant-like activity of Bacopa monnieri was facilitated through the serotonergic and adrenergic system. This also excludes any interaction with the opioid system.

The commonly used experimental models for screening prospective antidepressants are FST and TST models. These behavioural tests are relaying on the fact that rats or mice when forced to swim or are suspended in a restricted space, ultimately stop to struggle and they surrender themselves to the stressful conditions. The animals will take an immobile posture, which is taken as a state of depression, and is used to evaluate potential antidepressant drugs. ${ }^{21,22}$

The present study has shown that the acute administration of Bacopa monnieri by the oral route can produce an antidepressant-like response in mice. Moreover, it is noteworthy that the antidepressant-like effect produced by Bacopa monnieri is similar to the effect produced by fluoxetine, a classical antidepressant drug. The antidepressant activity of Bacopa monnieri is found with all the four doses tested, i.e., 20, 40, 80, and $120 \mathrm{mg} / \mathrm{kg}$, respectively. These results are in agreement with the reported antidepressant-like activity in a similar dose range of Bacopa monnieri. ${ }^{30}$ Although a clear-cut doseresponse relation was not observed with Bacopa monnieri treatment, a U-shaped trend was noticed in the FST model, which is a common trend with many of the conventional antidepressant drugs in behavioural studies. ${ }^{4}$

CNS stimulant drugs, such as cocaine or amphetamines, can decrease the duration of immobility in the FST. ${ }^{31}$ As opposed to the action of antidepressants; this is due to the CNS stimulant action, which brings about marked motor stimulation, resulting in an increased general activity of animals. Such psycho stimulant actions of drugs can produce a false-positive effect in the FST model. Hence to eliminate a false-positive effect in this study, locomotors activity was recorded using an actophotometer.

All the doses of Bacopa monnieri, which we employed in the present study, had no effect on the locomotors function of the animals in actophotometer performance, ruling out any stimulant effect on the CNS. Chatterjee et al, had observed that Bacopa monnieri treatment was devoid of any motor impairment in mice when tested on a rotarod and an animal activity monitor. ${ }^{17}$ This was further confirmed by our study that the antidepressant doses of
Bacopa monnieri will not impair the muscle tone or motor activity.

Bacopa monnieri contains a major constituent known as saponins also termed as "bacosides". 5 The pharmacological effects of Bacopa monnieri are due to the presence of these saponins, especially bacoside $\mathrm{A}$ and bacoside $\mathrm{B} .{ }^{32}$ The bacoside $\mathrm{A}$ is identified as a mixture of four triglycosidicsaponins, whereas bacoside B contains four diglycosidic saponins. Bacoside $\mathrm{A}$ has been reported to be responsible for promoting memory as well as anxiolytic activity and improve cognitive functions in animal models with Alzheimer's disease. ${ }^{33-35}$

In the pathophysiology and treatment of depression, much focus is given on the brain monoaminergic system. Depression has been associated with a deterioration in the noradrenergic and serotonergic neurotransmission. ${ }^{36,37}$ Hence, the present study made an attempt to investigate the activity of BM on the monoaminergic system in FST. The administration of PCPA for four consecutive days can deplete the endogenous stores of serotonin without affecting the noradrenergic or dopaminergic levels. ${ }^{19,38}$

In this study, after the pre-treatment with PCPA, the antidepressant-like effect produced in mice by BM was blocked, suggesting a role of the serotonergic system in the action of this plant extract. Furthermore, mice were pre-treated with various serotonin receptor antagonists. It was observed that the anti-immobility effect produced by Bacopa monnieri in the FST was abolished by the pretreatment of mice with pindolol and ketanserin, which are the $5-\mathrm{HT} 1 \mathrm{~A} / 1 \mathrm{~B}$ and $5-\mathrm{HT} 2 \mathrm{~A} / 2 \mathrm{~B}$ receptor antagonists. The 5HT3 receptor antagonist, ondansetron was unable to block the antidepressant-like effect exerted by Bacopa monnieri. These findings indicate that the antidepressantlike action of Bacopa monnieri involves an interaction with 5HT1 and 5HT2 serotonergic receptors.

The noradrenergic system has been a valuable target for antidepressants. Various reports indicate that the antidepressants can act by enhancing the availability of noradrenaline in the synaptic clefts. ${ }^{36}$ Hence in our study, mice pre-treated with $\alpha 1$ and $\alpha 2$ adrenoceptor blockers (prazosin and yohimbine, respectively), inhibited the antidepressant-like effect of Bacopa monnieri. These findings suggest that Bacopa monnieri may produce its antidepressant-like activity through the modulation of $\alpha 1$ and $\alpha 2$ adrenergic receptors.

Recently, the role of opioid receptors in the pathophysiology of depression was identified by various researchers. In the posterior thalamus and anterior cortex of depressed patients, a marked reduction in $\mu$-opioid receptor availability was reported. ${ }^{39,20}$ However, in our study after administering naloxone, mice showed no reversal of the anti-immobility effect produced by Bacopa monnieri, suggesting no participation of the opioid system in the antidepressant-like activity of Bacopa monnieri. 
The present study indicates the role of the monoaminergic system in the antidepressant-like activity of Bacopa monnieri. There may be other mechanisms also involved, which are not addressed in this work. The neuroprotective function of Bacopa monnieri is believed to be due to its antioxidant and antistress activities. The methanolic extract of Bacopa monnieri was found to have an antioxidant action, which reduces the oxidation and DNA damage in cultured rat astrocytes. ${ }^{40}$

It was shown that the Bacopa monnieri extract inhibits multiple components of the beta-amyloid-induced oxidative stress pathway that can contribute to alzheimer's pathology and reduced beta-amyloid levels in the brain of an alzheimer's disease (AD) transgenic mouse model. ${ }^{41}$ Bacopa monnieri was shown to be protective in the animal model of ischemia-induced brain injury and dementia models and its inhibitory effect on AchE activity may be responsible for its cognitive enhancing properties. ${ }^{42,43}$ Brain-derived neurotropic factor (BDNF), modulates the plasticity of neurons, inhibits cell death, and increases the cell survival proteins that are responsible for the proliferation and maintenance of central nervous system neuron. ${ }^{44}$ A recent study showed that the extract of Bacopa monnieri $(80-120 \mathrm{mg} / \mathrm{kg}$ ) and imipramine increased the BDNF expression in the hippocampus and frontal cortex of CUS-treated rats. ${ }^{44}$ This increase in the BDNF expression may be one of the mechanisms involved in the antidepressant-like activity of Bacopa monnieri.

\section{CONCLUSION}

The acute treatment with Bacopa Monnieri produced an antidepressant-like effect in behavioural models of depression in mice. The present study provides evidence that the antidepressant-like effect of Bacopa monnieri in forced swimming test is mediated through an interaction with the serotonergic (5-HT1A/1B and 5-HT2A/2B) and noradrenergic ( $\alpha 1$ and $\alpha 2$ adrenoceptors) systems. Furthermore, the anti-immobility effect of this plant extract does not seem to be dependent on 5-HT3 serotonergic receptors nor opioid receptors. However, future experimental studies may be needed to confirm these findings and to explore the possibility of other mechanisms.

Funding: No funding sources

Conflict of interest: None declared

Ethical approval: The study was approved by the Institutional Ethics Committee (1081/a/07/CPCSEA/I/6/7/2011)

\section{REFERENCES}

1. Reddy MS. Depression: the disorder and the brain. Indian J Psychol Med. 2010;32:1-2.

2. Lisa L, Moltke V, Greenblatt DJ. Medication dependence and anxiety. Dialogues in neurosciences. 2003;5:237-45.
3. Capra JC, Cunha MP, Msachado DG, Zomkowski AD, Mendes BG, Santos AR, et al. Antidepressant-like effect of scopoletin, a coumarin isolated from Polygala sabulosa (Polygalaceae) in mice: evidence for the involvement of monoaminergic systems. Eur J Pharmacol. 2010;643:232-8.

4. Girish C, Raj V, Arya J, Balakrishnan S. Evidence for the involvement of the monoaminergic system, but not the opioid system in the antidepressant-like activity of ellagic acid in mice. Eur $\mathbf{J}$ Pharmacol. 2012;682:118-25.

5. Russo A, Borrelli F. Bacopa monnieri, a reputed nootropic plant: An overview. Phytomed. 2005;12:305-17.

6. Sumathy T, Subramanian S, Govindasamy S, Balakrishna K, Veluchamy G. Protective effect of Bacopa monnierion morphine induced hepatotoxicity in rats. Phytother Res. 2001;15:643-5.

7. Channa S, Dar A, Yaqoob S, Yaqoob M, Atta-UrRahman. Anti-inflammatory activity of Bacopa monnieri in rodents. $\mathrm{J}$ Ethnopharmacol. 2006;104:286-9.

8. Rao CV, Sairam K, Goel RK. Experimental evaluation of Bocopa monnierion rat gastric ulceration and secretion. Indian $\mathbf{J}$ Physiol Pharmacol. 2000;44:435-41.

9. Bhattacharya SK, Bhattacharya A, Kumar A, Ghosal S. Antioxidant activity of Bacopa monnieriin rat frontal cortex, striatum and hippocampus. Phytother Res. 2000;14:174-9.

10. Kaster MP, Raupp I, Binfare RW, Andreatini R, Rodrigues AL. Antidepressant- like effect of lamotrigine in the mouse forced swimming test: evidence for the involvement of the noradrenergic system. Eur J Pharmacol. 2007;56:119-24.

11. D'Aquila PS, Collu M, Gessa GL, Serra G. The role of dopamine in the mechanism of action of antidepressant drugs. Eur J Pharmacol. 2000;405:365-73

12. Anguelova M, Benkelfat C, Turecki G. A systematic review of association studies investigating genes coding for serotonin receptors and the serotonin transporter: I. Affective disorders. Mol Psychiatry. 2003;8:574-91.

13. Anguelova M, Benkelfat C, Turecki G. A systematic review of association studies investigating genes coding for serotonin receptors and the serotonin transporter: II. Suicidal behavior. Mol Psychiatry. 2003;8:646-53.

14. Drevets WC. Neuroimaging and neuropathological studies of depression: implications for the cognitive-emotional features of mood disorders. Curr Opin Neurobiol. 2001;11:240-9.

15. Schreiber R, Brocco M, Audinot V, Gobert A, Veiga S, Millan MJ. (1-(2, 5-dimethoxy-4iodophenyl)-2-aminopropane)-induced head twitches in the rat are mediated by 5hydroxytryptamine $5-\mathrm{HT}_{2 \mathrm{~A}}$ receptors: modulation 
by novel $5-\mathrm{HT}_{2 \mathrm{~A} / 2 \mathrm{C}}$ antagonists, $\mathrm{D}_{1}$ antagonists and 5- $\mathrm{HT}_{1 \mathrm{~A}}$ agonists. J Pharmacol Exp Ther. 1995;273:101-12.

16. Brocardo PS, Budni J, Lobato KR, Santos AR, Rodrigues AL. Evidence for the involvement of the opioid system in the antidepressant-like effect of folic acid in the mouse forced swimming test. Behav Brain Res. 2009;200:122-7.

17. Chatterjee M, Verma P, Palit G. Comparative evaluation of Bacopa monniera and Panax quniquefolium in experimental anxiety and depressive models in mice. Indian $\mathbf{J}$ Exp Biol. 2010;8:306-13.

18. Wang R, Xu Y, Wu HL, Li YB, Li YH, Guo JB et. al. The antidepressant effects of curcumin in the forced swimming test involve $5-\mathrm{HT}_{1}$ and $5-\mathrm{HT}_{2}$ receptors. Eur J Pharmacol. 2007;578:43-50.

19. Yang CS, Tzou BC, Liu YP, Tsai MJ, Shyue SK, Tzeng SF. Inhibition of cadmium-induced oxidative injury in rat primary astrocytes by the addition of antioxidants and the reduction of intracellular calcium. $\mathrm{J}$ Cell Biochem. 2008;103:825-34.

20. Bruning CA, Souza AC, Gai BM, Zeni G, Nogueira CW. Antidepressant-like effect of $\mathrm{m}$ trifluoromethyl-diphenyl diselenide in the mouse forced swimming test involves opioid and serotonergic systems. Eur J Pharmacol. 2011b;658:145-9.

21. Steru L, Chermat R, Thierry B. The tail suspension test: a new method for screening antidepressants in mice. Psychopharmacology. 1985;85:367-70.

22. Porsolt RD, Bertin A, Jalfre M. Behavioral despair in mice: a primary screening test for antidepressants. Arch Int Pharmacodyn Ther. 1977;229:327-36.

23. Boissier JR, Simon P. Action of caffeine on the spontaneous motility of the mouse. Arch Int Pharmacodyn Ther.1965;158:212-21.

24. Devadoss T, Pandey DK, Mahesh R, Yadav SK. Effect of acute and chronic treatment with QCF-3 (4-benzylpiperazin-1-yl) (quinoxalin-2-yl) methanone, a novel $5-\mathrm{HT}_{(3)}$ receptor antagonist, in animal models of depression. Pharmacol Rep. 2010;62:245-57.

25. Dias ZA, Oscar RA, Lin J, Santos AR, Calixto JB, Lúcia Severo Rodrigues A. Evidence for serotonin receptor subtypes involvement in agmatine antidepressant-like effect in the mouse forced swimming test. Brain Res. 2004;1023:253-63.

26. Guilloux JP, David DJ, Guiard BP, Chenu F, Repérant C, Toth M, et al. Blockade of 5-HT1A receptors by $(+/-)$ - pindolol potentiates cortical 5HT outflow, but not antidepressant-like activity of paroxetine: microdialysis and behavioral approaches in 5-HT1A receptor knockout mice. Neuropsychopharmacology. 2006;31:2162-72.

27. Jesse CR, Wilhelm EA, Bortolatto CF, Nogueira $\mathrm{CW}$. Evidence for the involvement of the noradrenergic system, dopaminergic and imidazoline receptors in the antidepressant-like effect of tramadol in mice. Pharmacol Biochem Behav. 2010;95:344-50.

28. Redrobe JP, Bourin M. Partial role of 5- $\mathrm{HT}_{2}$ and 5$\mathrm{HT}_{3}$ receptors in the activity of antidepressants in the mouse forced swimming test. Eur J Pharmacol. 1997;325:129-35.

29. Yalcin I, Aksu F, Belzung C. Effects of desipramine and tramadol in a chronic mild stress model in mice are altered by yohimbine but not by pindolol. Eur J Pharmacol. 2005;514:165-74.

30. Sairam K, Rao CV, Babu MD, Goel RK. Prophylactive and curative effects of Bacopa monniera in gastric ulcer models. Phytomedicine. 2001;8:423-30.

31. Citó MCO, Silva MIG, Santos LK, Fernandes ML, Melo FH, Aguiar JA, et al. Antidepressantlike effect of Hoodia gordonii in a forced swimming test in mice: evidence for involvement of the monoaminergic system. Braz J Med Biol Res. 2015;48:57-66.

32. Singh HK, Dhawan BN. Neuro psycho pharmacological effects of the Ayurvedic nootropic Bacopa monnieri Linn. (Brahmi). Indian J Pharmacol. 1997;29:359-65.

33. Rastogi RP, Pal R, Kulshreshtha DK. Bacoside [A.sub.3]-a triterpinoid saponin from Bacopa monniera. Phytochemistry. 1994;36:133-7.

34. Bhattacharya SK, Ghosal S. Anxiolytic activity of a standardized extract of Bacopa monniera: an experimental study. Phytomed. 1998;5:77-82.

35. Bhattacharya SK, Kumar A, Ghosal S. Effect of Bacopa monniera on animal models of Alzheimer's disease and perturbed central cholinergic markers of cognition in rats. Res Com Pharmacol Toxicol. 1999;4:1-12.

36. Elhwuegi AS. Central monoamines and their role in major depression. Prog Neuropsychopharmacol Biol Psychiatry. 2004;28:435-51.

37. Millan MJ. The role of monoamines in the actions of established and "novel" antidepressant agents: a critical review. Eur J Pharmacol. 2004;500:371-84.

38. Eckeli AL, Dach F, Rodrigues AL. Acute treatment with GMP produce antidepressant-like effects in mice. Neuroreport. 2000;11:1839-43.

39. Kennedy SE, Koeppe RA, Young EA, Zubieta JK. Dysregulation of endogenous opioid emotion regulation circuitry in major depression in women. Arch Gen Psychiat. 2006;63:1199-208.

40. Russo A, Borrelli F, Campisi A, Acquaviva R, Raciti G, Vanella A. Nitric oxide-related toxicity in cultured astrocytes: effect of Bacopa monnieri. Life Sci. 2003;73:1517-26.

41. Dhanasekaran M, Tharakan B, Holcomb LA, Hitt AR, Young KA, Manyam BV. Neuroprotective mechanisms of ayurvedic antidementia botanical Bacopa monnieri. Phytother Res. 2007;21:965-9.

42. Saraf MK, Prabhakar S, Anand A. Neuroprotective effect of Bacopa monnieri on ischemia induced 
brain injury. Pharmacol Biochem Behav. 2010;97:192-7.

43. Das A, Shanker G, Nath C, Pal R, Singh S, Singh $\mathrm{H}$. A comparative study in rodents of standardized extracts of Bacopa monniera and Ginkgo biloba: Anticholinesterase and cognitive enhancing activities. Pharmacol Biochem Behav. 2002;73:893-900.
44. Banerjee R, Hazra S, Kumar GA, Mondal AC. Chronic administration of Bacopa Monniera increases BDNF protein and mRNA expressions: A study in chronic unpredictable stress induced animal model of depression. Psychiatry Investig. 2014;11:297-306.

Cite this article as: Girish C, Oommen S, Vishnu R. Evidence for the involvement of the monoaminergic system in the antidepressantlike activity of methanolic extract of Bacopa monnieri in albino mice. Int $\mathrm{J}$ Basic Clin Pharmacol 2016;5:914-22. 